\title{
Clinical Analysis of Neonates Born to Mothers with or without COVID-19: A Retrospective Analysis of 48 Cases from Two Neonatal Intensive Care Units in Hubei Province
}

Wei Liu, MD ${ }^{1, *}$ Hongbin Cheng, MD ${ }^{2, *}$ Jing Wang, MD ${ }^{1} \quad$ Lingli Ding, $\mathrm{BSc}^{1} \quad$ Zhaoxian Zhou, BSc ${ }^{1}$ Siying Liu, BSc ${ }^{1}$ Liwen Chang, MD $^{1}$ Zhihui Rong, MD $^{1}$

\footnotetext{
${ }^{1}$ Department of Pediatrics, Huazhong University of Science and Technology, Tongji Hospital, Tongji Medical College, Wuhan, Hubei, China

2 Department of Neonatology, HuangShi Maternal and Child Healthcare Hospital, Huangshi, Hubei, China
}

Address for correspondence Zhihui Rong, MD, Department of Neonatology, Huazhong University of Science and Technology, Tongji Hospital, Tongji Medical College, Wuhan 430030, China (e-mail: rongzhihui53@163.com).

\section{Abstract \\ Keywords \\ - coronavirus disease 2019 \\ - vertical transmission \\ - maternal-infant infection \\ - newborn}

Objective The perinatal consequences of neonates born to severe acute respiratory syndrome-associated coronavirus-2 (SARS-CoV-2) infected mothers are uncertain. This study aimed to compare the differences in clinical manifestation, laboratory results, and outcomes of neonates born to mothers with or without coronavirus disease 2019 (COVID-19).

Study Design A total of 48 neonates were admitted to Tongji Hospital and HuangShi Maternal and Child Healthcare Hospital from January 17 to March 4, 2020. The neonates were divided into three groups according to the mothers' conditions: neonates born to mothers with confirmed COVID-19, neonates born to mothers with clinically diagnosed COVID-19, and neonates born to mothers without COVID19. The clinical data of mothers and infants in the three groups were collected, compared, and analyzed.

Results The deliveries occurred in a negative pressure isolation room, and the neonates were separated from their mothers immediately after birth for further observation and treatment. None of the neonates showed any signs of fever, cough, dyspnea, or diarrhea. SARS-CoV-2 reverse transcriptase-polymerase chain reaction of the throat swab and feces samples from the neonates in all three groups was negative. No differences were detected in the whole blood cell, lymphocytes, platelet, and liver and renal function among the three groups. All mothers and their infants showed satisfactory outcomes, including a 28-week preterm infant.

Conclusion The clinical manifestations, radiological, and biochemical results did not show any difference between the three groups. No evidence of vertical transmission was found in this study whether the pregnant women developed coronavirus infection in the third (14 cases) or second trimester (1 case).

* These authors contributed equally to this work and shall be considered co-first authors.

received

June 19, 2020

accepted after revision

August 7, 2020

published online

September 6, 2020
DOI https://doi.org/

10.1055/s-0040-1716505.

ISSN 0735-1631.
Copyright $\odot 2020$ by Thieme Medical Publishers, Inc., 333 Seventh Avenue, New York, NY 10001, USA. Tel: +1(212) 760-0888.
License terms

(c) $(1) \ominus$ 


\section{Key points}

- Characteristics of neonates born to mothers with and without COVID-19 have been compared.

- All the 48 cases presented in the study had good outcomes.

- A 28-week preterm born to COVID-19 mother presented to be clear of SARS-COV-2 infection.

In the past few decades, newly evolved coronaviruses, such as severe acute respiratory syndrome coronavirus (SARS$\mathrm{CoV}$ ) and Middle East respiratory syndrome coronavirus (MERS-CoV), have become a global threat to public health. ${ }^{1}$ In December 2019, a new coronavirus causing a pneumonia epidemic worldwide, different from SARS-CoV and MERS$\mathrm{CoV}$, was identified and named as coronavirus disease 2019 (COVID-19) by the World Health Organization. ${ }^{2}$ The pathogen, labeled SARS-CoV-2, belongs to the $\beta$-type coronavirus. As of June 19, 2020, over 844,000 COVID-19 cases had been confirmed worldwide, causing at least 45,000 deaths. For the diagnosis of COVID-19, the SARS-CoV-2 antigen should test positive in respiratory specimens in addition to typical respiratory symptoms and lung images; also, specific antibodies of the virus from plasma play a crucial role for the diagnosis of the disease. ${ }^{3,4}$ Pregnant women have been found infected with COVID-19 in their late pregnancy, and their newborns' perinatal consequences have been reported; no vertical transmission of SARS-CoV-2 was observed and no perinatal complications were detected. ${ }^{5-7}$ Currently, we still lack information about whether the newborn's perinatal consequences are different between pregnant women with COVID-19 and those without the infection. ${ }^{8}$

In the present study, the clinical data of neonates born to mothers with confirmed COVID-19, neonates born to mothers with clinically diagnosed COVID-19, and neonates born to mothers without COVID-19 were compared and analyzed. To the best of our knowledge, this is the first report to compare the differences in clinical characteristics of neonates born to mothers with or without COVID-19. One preterm infant born to COVID-19 mother and delivered in the second trimester was also reported in this study.

\section{Materials and Methods}

\section{Patients and Grouping}

Neonates born to suspected COVID-19 mothers, admitted to Tongji Hospital and HuangShi Maternal and Child Healthcare Hospital from January 17 to March 4, 2020, were included in this study. Tongji hospital is located in central Wuhan, and HuangShi Maternal and Child Healthcare Hospital is located in Huangshi, $80 \mathrm{~km}$ away from Wuhan. This study was approved by the ethics commission of Tongji Hospital, Huazhong University of Science and Technology. Informed consent was obtained from the guardians of all the included patients.

At the peak of the COVID-19 outbreak in China, all pregnant women from Hubei province were considered to have marked epidemiological links, and hence, they were required to screen for SARS-COV-2 infection before delivery during that time. The screening tests included nasopharynx swab (at least twice) and chest computed tomography (CT) scan. The screening test results could not be obtained for some emergency admissions shortly after the neonates were born. Hence, those infants were isolated to neonatal intensive care unit (NICU) until the mother was confirmed to be clear of infection. When receiving the test results from the mothers, the infants were divided into three groups: (1) infants born to confirmed COVID-19 cases: defined as the mother with respiratory specimens that tested positive for the SARS-CoV-2; (2) infants born to clinically diagnosed COVID-19 cases: defined as a typical clinical symptoms and chest CT with COVID-19 pneumonia, whereas the viral nucleic acid test for SARS-CoV-2 was reported negative and ruled out other virus infection; and (3) infants born to control cases: defined as mothers with or without respiratory symptoms and the origin of infection was confirmed as influenza A or B. ${ }^{7,9,10}$

Samples from amniotic fluid, placental swab, gastric lavage fluid of the neonates right after birth, neonatal serum, throat swab, and feces were collected to test SARS-CoV-2 by polymerase chain reaction (PCR).

\section{Data Collection}

The maternal and neonatal information included the following: clinical symptoms of the mothers, clinical manifestation, laboratory, and radiological results of the neonates.

\section{Statistical Analysis}

The statistical software SPSS for Windows version 19 was used for data analyses. Continuous distribution variables were expressed as mean \pm standard deviation. Categorical variables were summarized as numbers and percentages. Analysis of variance (ANOVA) was used to analyze for homogeneity ANOVA, followed by post hoc testing. If the continuous variables were normalized distribution, Tamhane's T2 were used as the pos hoc test for nonhomogeneous ANOVA result; if the continuous variables are not normalized distribution, nonparameter test was used. A $p$-value $<0.05$ was considered significant difference.

\section{Results}

\section{Comparison of Clinical Characteristics of Mothers in the Three Groups}

The three groups consisted of 15,17 , and 16 neonates, respectively, as described above. All deliveries occurred in a negative pressure isolation room, and the neonates were immediately separated from the mothers according to the protocol. ${ }^{7}$ All pregnancies were uneventful until this admission. All the mothers from the three groups reside in the epidemic area of Hubei Province.

The most common onset symptoms were fever $(10 / 15$, $67 \%)$ and cough $(6 / 15,40 \%)$ in the mothers with confirmed COVID-19, which is significantly higher than those in the 
Table 1 Clinical characteristic of pregnant women

\begin{tabular}{|c|c|c|c|}
\hline & Confirmed $(n=15)$ & Suspected $(n=17)$ & Control $(n=16)$ \\
\hline $\begin{array}{l}\text { Age, y } \\
\text { Mean } \pm \text { SD }\end{array}$ & $32 \pm 2.67$ & $29.59 \pm 3.14$ & $30.88 \pm 3.27$ \\
\hline $\begin{array}{l}\text { Gestational age, wk } \\
\text { Median (IQR) }\end{array}$ & $37.41 \pm 1.80$ & $38.78 \pm 0.89$ & $38.33 \pm 1.49$ \\
\hline \multicolumn{4}{|l|}{ Parity } \\
\hline Nulliparous, $n(\%)$ & $5(33.3)$ & $7(41.2)$ & $6(37.5)$ \\
\hline Multiparous, $n(\%)$ & $10(66.7)$ & $10(58.8)$ & $10(62.5)$ \\
\hline \multicolumn{4}{|l|}{ Delivery mode } \\
\hline Cesarean, $n(\%)$ & $14(93.3)$ & $15(88.2)$ & $13(81.2)$ \\
\hline Vaginal delivery, $n(\%)$ & $1(6.7)$ & $2(11.8)$ & $3(18.8)$ \\
\hline \multicolumn{4}{|l|}{ Pregnancy complications } \\
\hline Hypertensive disorders, $n(\%)$ & $2(13.3)$ & $1(6.7)$ & $1(6.7)$ \\
\hline Gestational diabetes mellitus, $n(\%)$ & $2(13.3)$ & $3(20)$ & $2(13.3)$ \\
\hline Chorioamnionitis, $n$ (\%) & $2(13.3)$ & $1(6.7)$ & $1(6.7)$ \\
\hline \multicolumn{4}{|l|}{ Delivery detail } \\
\hline Turbid amniotic fluid, $n$ (\%) & $3(20)$ & $4(23.5)$ & $0(0)$ \\
\hline Cord around neck, $n(\%)$ & $0(0)$ & $2(11.8)$ & $3(18.8)$ \\
\hline Postpartum hemorrhage, $n(\%)$ & $1(6.7)$ & $0(0)$ & $3(18.8)$ \\
\hline \multicolumn{4}{|l|}{ Maternal clinical symptoms and treatment } \\
\hline Fever, $n(\%)$ & $10(66.7)$ & $8(47.1)$ & $2(12.5)$ \\
\hline Cough, $n(\%)$ & $6(40)$ & $2(11.8)$ & $1(6.3)$ \\
\hline Diarrhea, $n(\%)$ & $1(6.7)$ & $1(5.9)$ & 0 \\
\hline Prenatal antiviral treatment, $n(\%)$ & $10(66.7)$ & $1(5.9)$ & 0 \\
\hline Prenatal steroid, $n(\%)$ & $1(6.7)$ & $2(11.8)$ & 0 \\
\hline
\end{tabular}

Abbreviations: IQR, interquartile range; SD, standard deviation.

\begin{tabular}{|c|c|c|c|c|}
\hline & Confirmed $(n=15)$ & Suspected $(n=17)$ & Control $(n=16)$ & $p$-Value \\
\hline $\begin{array}{l}\text { White blood cell }\left(\times 10^{9} \text { cells } / \mathrm{L}\right) \\
\text { Mean } \pm \text { SD }\end{array}$ & $8.04 \pm 2.28$ & $8.95 \pm 1.74$ & $9.71 \pm 2.11$ & 0.236 \\
\hline $\begin{array}{l}\text { Lymphocytes }\left(\times 10^{9} \text { cells/L) }\right. \\
\text { Mean } \pm \text { SD }\end{array}$ & $1 \pm 0.27$ & $1.36 \pm 0.26$ & $1.46 \pm 0.29$ & $\begin{array}{l}0.008^{a} \\
0.001^{b} \\
0.403^{c}\end{array}$ \\
\hline Neutrophil $\left(\times 10^{9}\right.$ cells/L) Mean \pm SD & $6.5 \pm 2.1$ & $7.09 \pm 1.76$ & $7.61 \pm 1.98$ & 0.474 \\
\hline Platelets $\left(\times 10^{9}\right.$ cells $\left./ \mathrm{L}\right)$ Mean \pm SD & $178.67 \pm 48.8$ & $209.59 \pm 52.41$ & $215.63 \pm 56.16$ & 0.348 \\
\hline C-reactive protein $(\mathrm{g} / \mathrm{L})$ Mean \pm SD & $13.37 \pm 11.81$ & $3.71 \pm 4.08$ & $3.24 \pm 3.97$ & 0.098 \\
\hline $\begin{array}{l}\text { Alanine transaminase (IU/L) } \\
\text { Mean } \pm \text { SD }\end{array}$ & $21.53 \pm 18.85$ & $11.88 \pm 3.4$ & $10.75 \pm 3.38$ & 0.801 \\
\hline $\begin{array}{l}\text { Aspartate transaminase (IU/L) } \\
\text { Mean } \pm \text { SD }\end{array}$ & $35.93 \pm 28.41$ & $18.77 \pm 3.87$ & $17.38 \pm 3.89$ & 0.260 \\
\hline $\begin{array}{l}\text { Urea }(\mu \mathrm{mol} / \mathrm{L}) \\
\text { Mean } \pm \mathrm{SD}\end{array}$ & $2.44 \pm 0.78$ & $3.01 \pm 0.75$ & $3.49 \pm 0.76$ & $\begin{array}{l}0.104^{a} \\
0.004^{b} \\
0.165^{c}\end{array}$ \\
\hline $\begin{array}{l}\text { Creatinine }(\mu \mathrm{mol} / \mathrm{L}) \\
\text { Mean } \pm S D\end{array}$ & $49.7 \pm 5.75$ & $44.72 \pm 6.76$ & $53.02 \pm 5.39$ & $\begin{array}{l}0.097^{a} \\
0.202^{b} \\
0.006^{c}\end{array}$ \\
\hline
\end{tabular}

Abbreviations: IQR, interquartile range; SD, standard deviation.

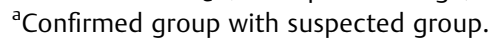

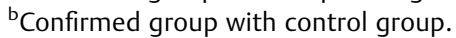

'Suspected group with control group. 

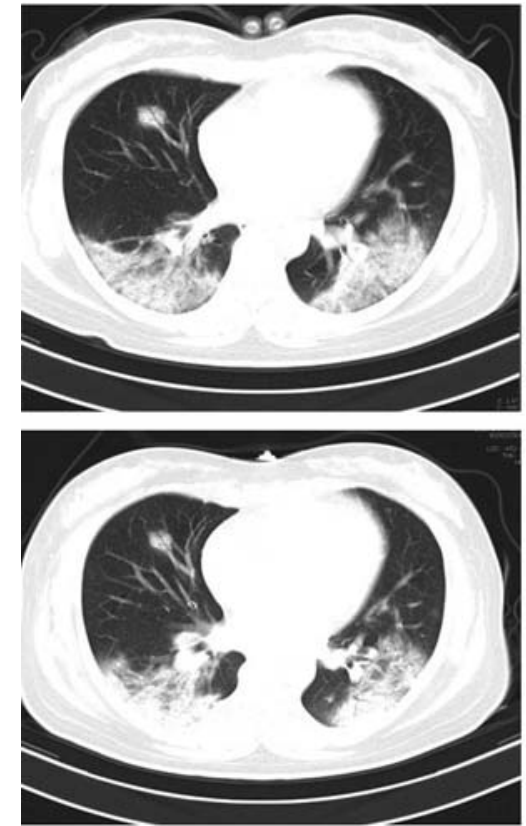

A
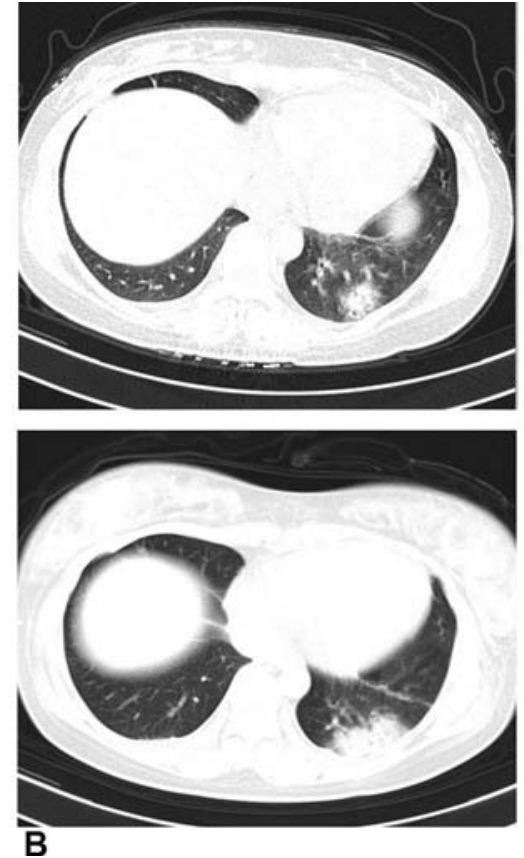

B
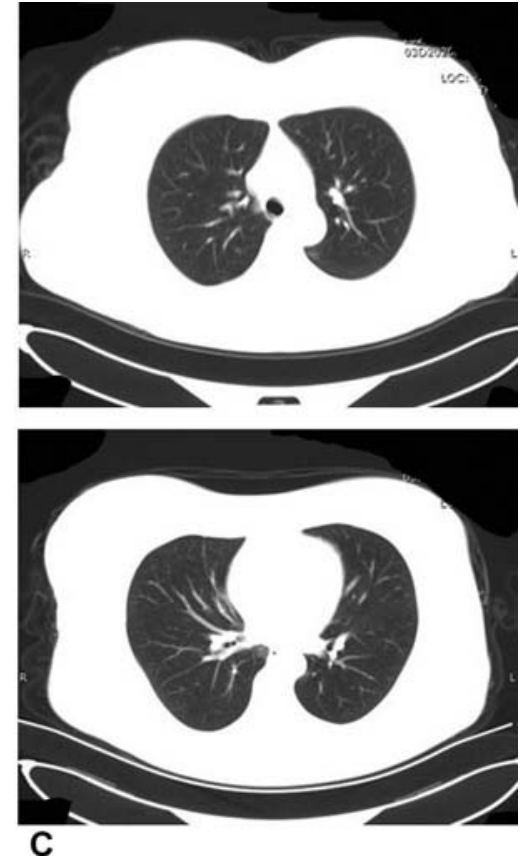

Fig. 1 Chest computed tomography scans of the mothers.

clinical diagnosis and control groups. Most of the mothers received antiviral treatment $(10 / 15,67 \%)$ in the confirmed group, while only one patient received the treatment in the clinically diagnosed group, and none received the same treatment in the control group ( - Table 1 ).

Furthermore, no differences were detected in the laboratory results except that lymphocytes decreased significantly in the confirmed group $\left(1 \pm 0.27 \times 10^{9}\right.$ cells/L) as compared with the other two groups $\left(1.36 \pm 0.26 \times 10^{9}\right.$ cells/L and $1.46 \pm 0.29 \times 10^{9}$ cells/L, respectively; $\left.p<0.01\right)$. The C-reactive protein increased significantly in the confirmed group $(8.43 \mathrm{~g} / \mathrm{L})$ as compared with the other two groups (1.12 and $0.5 \mathrm{~g} / \mathrm{L}$, respectively; $p<0.05$ ) ( - Table 2 ).

Chest CT scan in the COVID-19 confirmed ( - Fig. 1A) and clinically diagnosed groups ( - Fig. 1B) showed changes in the typical viral pneumonia, such as decreased diffuse and bilateral ground-glass opacities, patchy lung consolidation, blurred borders, and lesions merged into strips, ${ }^{7}$ while chest CT scan in the control group was normal ( - Fig. 1C).

\section{Comparison of Clinical Characteristics of Neonates in the Three Groups}

All the neonates were isolated in NICU for at least 14 days. None of the neonates from the three groups showed any signs of fever, cough, dyspnea, or diarrhea.

The gestational age of the neonates born to confirmed mothers was $37.41 \pm 1.80$ weeks, which was about 1 week earlier than the other two groups $(38.78 \pm 0.89$ and $38.33 \pm 1.49$ weeks, respectively). The birthweight in the neonates born to confirmed mothers was $3,001 \pm 321 \mathrm{~g}$, which was decreased as compared with the other groups ( $3,452 \pm 339$ and $3,048 \pm 378 \mathrm{~g}$, respectively). The laboratory results of the neonates of 24 hours of age are summarized below. No differences were detected in the whole blood cell, lymphocytes, platelet, and liver and renal function among the three groups $(p>0.05)$. Also, the C-reactive protein and markers of myocardial injury (protein B-type natriuretic peptide [NT-proBNP] and cardiac troponin I) did not differ among the three groups ( - Table 3 ), and the chest X-ray of the neonates was normal in the three groups ( - Fig. 2 ).

None of the neonates developed any clinical, radiological, hematological, or biochemical evidence of COVID-19. Samples from amniotic fluid, placental swab, gastric lavage fluid of the neonates right after birth, neonatal serum, throat swab, and feces were negative for SARS-CoV-2 by PCR.

A $28^{1 / 7}$ weeks of gestational age of male preterm neonate (birthweight 1,530 g) was born to a COVID-19 mother, who received dexamethasone ( $6 \mathrm{mg}$, every 12 hours, twice) and did not finish the course before delivery. The neonate showed respiratory distress shortly after birth, and bilateral lung ground glass with air bronchogram could be seen in the chest X-ray, which was consistent with neonatal respiratory distress syndrome ( - Fig. 3A). After two doses of surfactant administered through the endotracheal tube, the respiratory condition of the infant improved ( - Fig. 3B). He was on continuous positive airway pressure for 18 days and nasal cannula for another 2 weeks, and was discharged home at $34^{5 / 7}$ weeks of corrected gestational age and weight $1,980 \mathrm{~g}$ (-Fig. 3C). The infant was on oral caffeine for another 2 weeks after discharge. He showed grade I intraventricular hemorrhage and mild bronchopulmonay dysplasia and without retinopathy of prematurity. SARS-CoV-2 reverse transcription PCR in the throat swab sample from this preterm neonate and specific SARS-CoV-2 antibodies tested in the baby's plasma were negative.

\section{Discussion}

This is the first study to compare the differences in the clinical features and outcomes of neonates born to mothers with or 
Table 3 Clinical characteristics and laboratory results of the neonates

\begin{tabular}{|c|c|c|c|c|}
\hline & Confirmed $(n=15)$ & Suspected $(n=17)$ & Control $(n=16)$ & p-Value \\
\hline Gender (male/female) & $9 / 6$ & $9 / 8$ & $6 / 10$ & \\
\hline Apgar's score at 5 min median (IQR) & $9(8-9)$ & $9(8-9)$ & $9(8-10)$ & \\
\hline SGA, $n(\%)$ & $0(0)$ & $0(0)$ & $0(0)$ & \\
\hline $\begin{array}{l}\text { Birthweight, g } \\
\text { Mean } \pm \text { SD }\end{array}$ & $3,001 \pm 321$ & $3,452 \pm 339$ & $3,048 \pm 378$ & $\begin{array}{l}0.009^{a} \\
0.78^{b} \\
0.016^{c}\end{array}$ \\
\hline $\begin{array}{l}\text { White blood cell }\left(\times 10^{9} \text { cells } / \mathrm{L}\right) \\
\text { Mean } \pm \text { SD }\end{array}$ & $14.11 \pm 4.34$ & $17.97 \pm 7.18$ & $16.33 \pm 7.32$ & 0.254 \\
\hline $\begin{array}{l}\text { Lymphocytes }\left(\times 10^{9} \text { cells } / \mathrm{L}\right) \\
\text { Mean } \pm \mathrm{SD}\end{array}$ & $4.01 \pm 1.19$ & $3.72 \pm 1.27$ & $3.94 \pm 1.22$ & 0.860 \\
\hline $\begin{array}{l}\text { Neutrophil }\left(\times 10^{9} \text { cells } / \mathrm{L}\right) \\
\text { Mean } \pm \text { SD }\end{array}$ & $8.39 \pm 3.04$ & $12.40 \pm 4.43$ & $10.58 \pm 4.99$ & 0.121 \\
\hline $\begin{array}{l}\text { Hemoglobin }(g / d L) \\
\text { Mean } \pm S D\end{array}$ & $174.47 \pm 19.42$ & $179.53 \pm 32.09$ & $177.69 \pm 15.81$ & 0.829 \\
\hline $\begin{array}{l}\text { Platelets }\left(\times 10^{9} \text { cells } / \mathrm{L}\right) \\
\text { Mean } \pm \mathrm{SD}\end{array}$ & $233.47 \pm 62.44$ & $285.71 \pm 40.5$ & $260.44 \pm 42.13$ & 0.062 \\
\hline $\begin{array}{l}\text { C-reactive protein }(\mathrm{g} / \mathrm{L}) \\
\text { Mean } \pm \text { SD }\end{array}$ & $0.97 \pm 0.88$ & $1.92 \pm 2.25$ & $2.98 \pm 4.18$ & 0.952 \\
\hline $\begin{array}{l}\text { Alanine transaminase (IU/L) } \\
\text { Mean } \pm S D\end{array}$ & $13 \pm 6.53$ & $11.94 \pm 6.51$ & $12 \pm 4.75$ & 0.937 \\
\hline $\begin{array}{l}\text { Aspartate transaminase (IU/L) } \\
\text { Mean } \pm S D\end{array}$ & $47.8 \pm 22.27$ & $77.12 \pm 61.37$ & $52 \pm 19.75$ & 0.659 \\
\hline $\begin{array}{l}\text { Urea }(\mu \mathrm{mol} / \mathrm{L}) \\
\text { Mean } \pm \mathrm{SD}\end{array}$ & $2.91 \pm 0.78$ & $3.58 \pm 0.78$ & $3.06 \pm 1.00$ & 0.182 \\
\hline $\begin{array}{l}\text { Creatinine }(\mu \mathrm{mol} / \mathrm{L}) \\
\text { Mean } \pm \mathrm{SD}\end{array}$ & $59.93 \pm 6.88$ & $65.71 \pm 14.43$ & $57.88 \pm 11.78$ & 0.399 \\
\hline $\begin{array}{l}\text { Cystatin C (mg/L) } \\
\text { Mean } \pm \text { SD }\end{array}$ & $1.89 \pm 0.14$ & $1.74 \pm 0.23$ & $1.81 \pm 0.15$ & 0.716 \\
\hline $\begin{array}{l}\text { Urinary } \beta 2 \text { microglobulin }(\mathrm{mg} / \mathrm{L}) \\
\text { Mean } \pm \mathrm{SD}\end{array}$ & $3.20 \pm 1.03$ & $3.45 \pm 1.71$ & $3.62 \pm 1.10$ & 0.942 \\
\hline $\begin{array}{l}\text { NT-proBNP }(\mathrm{pg} / \mathrm{mL}) \\
\text { Mean } \pm \text { SD }\end{array}$ & $2,253 \pm 1317.7$ & $5,278.9 \pm 4186.8$ & $3,062.8 \pm 1591.3$ & 0.459 \\
\hline $\begin{array}{l}\text { Cardiac troponin I (ug/L) } \\
\text { Mean } \pm \text { SD }\end{array}$ & $12.83 \pm 6.42$ & $33.41 \pm 28.49$ & $46.46 \pm 21.65$ & 0.176 \\
\hline
\end{tabular}

Abbreviations: NT-proBNP, N-terminal pro-brain natriuretic peptide; IQR, interquartile range; SD, standard deviation.

${ }^{\mathrm{a} C o n f i r m e d ~ g r o u p ~ w i t h ~ s u s p e c t e d ~ g r o u p . ~}$

${ }^{\text {b } C o n f i r m e d ~ g r o u p ~ w i t h ~ c o n t r o l ~ g r o u p . ~}$

'Suspected group with control group.

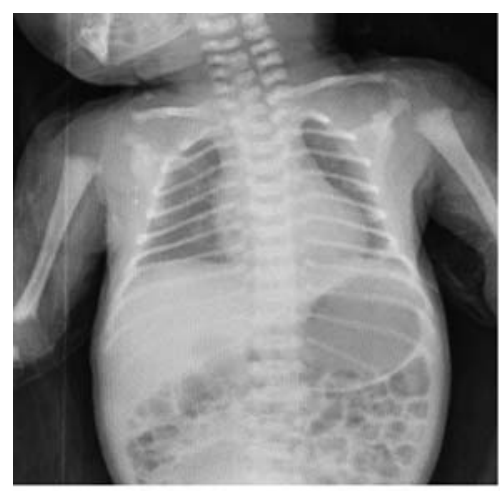

A

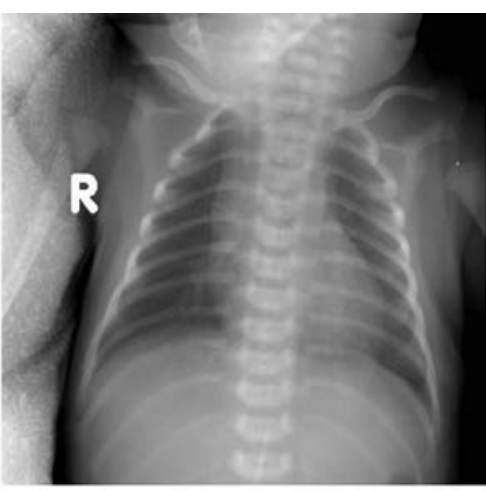

B

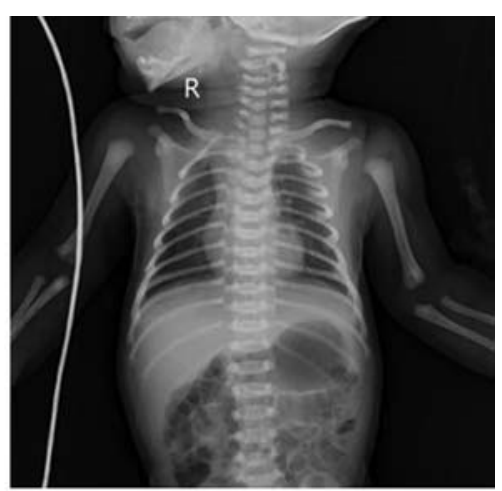

C

Fig. 2 Chest X-ray of the neonates from the three groups. 


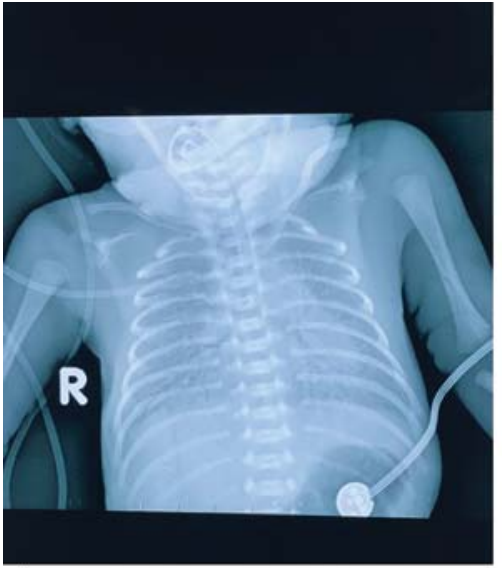

A

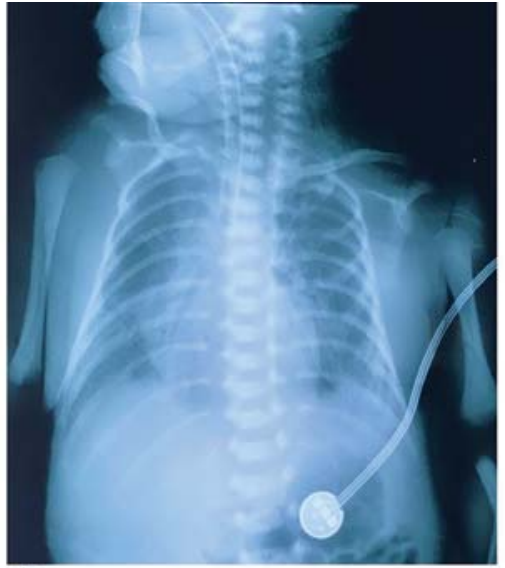

B

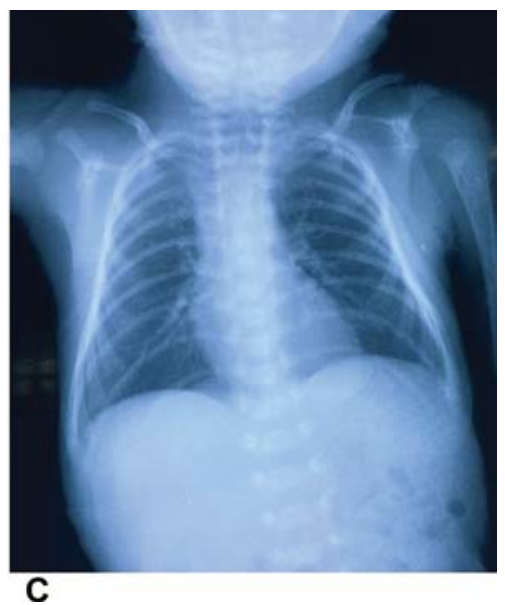

Fig. 3 Chest X-ray of the 28 weeks of preterm neonate.

without COVID-19. Together, 48 mothers and their infants were presented in this study showed satisfactory outcomes.

The SARS-CoV- 2 pathogen belongs to the $\beta$-type coronavirus. ${ }^{11}$ The case fatality rate of COVID- 19 is $<3 \%$ in the whole population, which implies that SARS-CoV-2 does not seem to cause the high-fatality rates previously observed for SARS and MERS-CoV, 10 and 37\%, respectively. ${ }^{12-14}$ Biopsy of a patient who suffered from COVID-19 showed overactivation of $\mathrm{T}$ cells, manifested by an increase of Th17 and high cytotoxicity of CD8 T cells, which partially accounted for the severe immune injury in this patient. ${ }^{15}$ The current results showed that lymphocytes decreased significantly in COVID-19 confirmed mothers as compared with the other two groups, which is probably due to the consumption of the lymphocytes. Assiri et al reported five cases of pregnant women infected with MERS-CoV from Saudi Arabia; of these, two died during the pregnancy. ${ }^{16,17}$ In the present study, all pregnant women survived with no complications, which indicated that SARS-CoV-2 does not have a high-fatality rate as that of MERS-CoV.

Reportedly, SARS could lead to severe intrauterine growth retardation, which could be due to the prolonged usage of a systemic high dose of corticosteroids or antiviral medicine. ${ }^{18}$ Herein, the average birthweight in the neonates born to confirmed COVID-19 mothers was significantly decreased as compared with the other groups. Except for one 28-week preterm delivery, all the other cases delivered infants at term or near term, and the birthweight of all the babies was appropriate for gestational age. The majority of the mothers received antiviral treatment (Chinese herbs) in the confirmed group (10/15, 67\%), and one of the mothers received prenatal steroids due to preterm delivery at 28 weeks. Both prenatal antiviral drugs and prenatal steroids did not exert any effect on the offspring.

Several studies have reported that no perinatal consequences were evident when pregnant women develop COVID-19 in the third trimester. ${ }^{5-7}$ Recent data indicated that angiotensinconverting enzyme-2 receptors have very low expression in the placenta, which makes the chance of SARS-CoV-2 vertical transmission almost impossible. ${ }^{7,19}$ In the current study, a 28-week preterm infant born to confirmed COVID-19 mother was clear of SARS-CoV-2 infection, implying that no perinatal consequences are evident when pregnant women develop COVID-19 in the second trimester. To the best of our knowledge, this is the first report, wherein a neonate born to mother with confirmed COVID-19 was delivered in the second trimester. This information must be considered with caution as this conclusion is only based on one case.

Nonetheless, the present study has some limitations. First, it is a very small observational cohort study, and additional evidence is needed to verify the potential vertical transmission. Second, according to Zeng et $\mathrm{al}^{20} 3 / 33$ (9\%) infants presented early-onset SARS-CoV-2 infection confirmed by transient nasopharyngeal and anal swab samples positive for SARS-CoV-2 on days 2 and 4 of life. A similar finding reported by $\mathrm{Yu}$ et al showed that transient throat swab PCR was positive at 36 hours of age. ${ }^{21}$ However, whether this phenomenon is a true vertical transmission or contamination with maternal secretion is yet controversial. ${ }^{22,23}$ Herein, we only tested the nasopharyngeal swab samples for SARS-CoV2 at 0 hours, 24 hours, and 7 days of age, and were found to be negative, which might due to the missed window. Third, some recently published studies showed that IgM, which is not usually transferred from mother to fetus because of its larger macromolecular structure, was elevated in 2 infants. Although SARS-CoV-2 was not detected in the serum or throat swab samples in these infants, it needed further evaluation to exclude vertical transmission. ${ }^{24-26}$ In the current study, we did not test the plasma for IgG and IgM antibodies of SARS-CoV-2 in neonates routinely because the detection kit for SARS-CoV-2 antibodies has just been developed and there is lack of a normal range for newborns. Although the positive and negative cutoff values for screening are also debatable, it gives us the insight to investigate the novel virus. However, additional samples and prolonged follow-up are needed to confirm the presence of vertical transmission.

\section{Conclusion}

The clinical manifestation, radiological, and biochemical results did not show any difference among the neonates 
born to mothers with and without COVID-19. In the present study, there was no evidence of vertical transmission irrespective of the pregnant women developed coronavirus infection in the third trimester (14 cases) or the second trimester (1 case). Because this is a study with a relatively small population, additional evidence is essential to verify the potential vertical transmission.

\section{Funding}

None.

\section{Conflict of Interest}

None declared.

\section{References}

1 Phan T. Novel coronavirus: from discovery to clinical diagnostics. Infect Genet Evol 2020;79:104211

2 Yu F, Du L, Ojcius DM, Pan C, Jiang S. Measures for diagnosing and treating infections by a novel coronavirus responsible for a pneumonia outbreak originating in Wuhan, China. Microbes Infect 2020;22(02):74-79

3 Liu W, Zhang Q, Chen J, et al. Detection of COVID-19 in children in early January 2020 in Wuhan, China. N Engl J Med 2020;382(14): 1370-1371

4 Long QX, Liu BZ, Deng HJ, et al. Antibody responses to SARS-CoV-2 in patients with COVID-19. Nat Med 2020;26(06):845-848

5 Chen $\mathrm{H}$, Guo J, Wang C, et al. Clinical characteristics and intrauterine vertical transmission potential of COVID-19 infection in nine pregnant women: a retrospective review of medical records. Lancet 2020;395(10226):809-815

6 Zhu H, Wang L, Fang C, et al. Clinical analysis of 10 neonates born to mothers with 2019-nCoV pneumonia. Transl Pediatr 2020;9 (01):51-60

7 Liu W, Wang J, Li W, Zhou Z, Liu S, Rong Z. Clinical characteristics of 19 neonates born to mothers with COVID-19. Front Med 2020; 14(02):193-198

8 Qiancheng X, Jian S, Lingling P, et al; sixth batch of Anhui medical team aiding Wuhan for COVID-19. Coronavirus disease 2019 in pregnancy. Int J Infect Dis 2020;95:376-383

9 Li Q Guan X, Wu P, et al. Early transmission dynamics in wuhan, china, of novel coronavirus-infected pneumonia. N Engl J Med 2020;382(13):1199-1207

10 Yan J, Guo J, Fan C, et al. Coronavirus disease 2019 in pregnant women: a report based on 116 cases. Am J Obstet Gynecol 2020; 223(01):111.e1-111.e14

11 Zhou G, Chen S, Chen Z. Back to the spring of 2020: facts and hope of COVID-19 outbreak. Front Med 2020;14(02):113-116
12 Huang C, Wang Y, Li X, et al. Clinical features of patients infected with 2019 novel coronavirus in Wuhan, China. Lancet 2020;395 (10223):497-506

13 Wang Y, Wang Y, Chen Y, Qin Q. Unique epidemiological and clinical features of the emerging 2019 novel coronavirus pneumonia (COVID-19) implicate special control measures. J Med Virol 2020;92(06):568-576

14 Biscayart C, Angeleri P, Lloveras S, Chaves TDSS, Schlagenhauf P, Rodríguez-Morales AJ. The next big threat to global health? 2019 novel coronavirus (2019-nCoV): what advice can we give to travellers? - Interim recommendations January 2020, from the Latin-American society for Travel Medicine (SLAMVI). Travel Med Infect Dis 2020;33:101567

15 Xu Z, Shi L, Wang Y, et al. Pathological findings of COVID-19 associated with acute respiratory distress syndrome. Lancet Respir Med 2020;8(04):420-422

16 Assiri A, Abedi GR, Al Masri M, Bin Saeed A, Gerber SI, Watson JT. Middle east respiratory syndrome coronavirus infection during pregnancy: a report of 5 cases from Saudi Arabia. Clin Infect Dis 2016;63(07):951-953

17 Wu D, Wu T, Liu Q Yang Z. The SARS-CoV-2 outbreak: what we know. Int J Infect Dis 2020;94:44-48

18 Shek CC, Ng PC, Fung GP, et al. Infants born to mothers with severe acute respiratory syndrome. Pediatrics 2003;112(04):e254

19 Zheng QL, Duan T, Jin LP. Single-cell RNA expression profiling of ACE2 and AXL in the human maternal-Fetal interface. Reproductive and Developmental Medicine 2020. Doi: 10.4103/20962924.278679

20 Zeng L, Xia S, Yuan W, et al. Neonatal early-onset infection with SARS-CoV-2 in 33 neonates born to mothers with COVID-19 in Wuhan, China. JAMA Pediatr 2020;174(07):722-725

21 Yu N, Li W, Kang Q, et al. Clinical features and obstetric and neonatal outcomes of pregnant patients with COVID-19 in Wuhan, China: a retrospective, single-centre, descriptive study. Lancet Infect Dis 2020;20(05):559-564

22 Kimberlin DW, Stagno S. Can SARS-CoV-2 infection be acquired in utero?: more definitive evidence is needed JAMA 2020

23 Dong L, Tian J, He S, et al. Possible vertical transmission of SARSCoV-2 from an infected mother to her newborn. JAMA 2020;323 (18):1846-1848

24 Zeng H, Xu C, Fan J, et al. Antibodies in infants born to mothers with COVID-19 pneumonia. JAMA 2020;323(18):1848-1849

25 Schwartz DA, Graham AL. Potential maternal and infant outcomes from (Wuhan) coronavirus 2019-nCoV infecting pregnant women: lessons from SARS, MERS, and other human coronavirus infections. Viruses 2020;12(02):194

26 Mimouni F, Lakshminrusimha S, Pearlman SA, Raju T, Gallagher PG, Mendlovic J. Perinatal aspects on the COVID-19 pandemic: a practical resource for perinatal-neonatal specialists. J Perinatol 2020;40(05):820-826 